\title{
Clinical utility of telomere length measurements in cancer
}

Chris Pepper ${ }^{1}$, Kevin Norris ${ }^{2}$ and Christopher Fegan ${ }^{2}$

${ }^{1}$ Brighton and Sussex Medical School, University of Sussex, Brighton, BN1 9PX. 2Division of Cancer \& Genetics, Cardiff University Medical School, Cardiff, CF14 4XN.

Corresponding author: Chris Pepper, c.pepper@bsms.ac.uk

Brighton and Sussex Medical School, University of Sussex, Brighton, BN1 9PX.

Tel: $+44(0) 1273678644$

Kevin Norris, NorrisKT@cardiff.ac.uk

Christopher Fegan, Christopher.fegan@wales.nhs.uk

Word count: 2084

\section{Declaration of Interest}

All three authors are co-inventors of patents relevant to the content of this manuscript and hold shares in a University spin-out company, TeloNostiX Ltd., set up to provide telomere length testing.

\footnotetext{
Abstract (word count $=113$ )

Cancer remains one of the leading causes of death in the developed world and despite impressive advances in therapeutic modalities, only a small subset of patients are currently cured. The underlying genetic heterogeneity of cancers clearly plays a critical role in determining both the clinical course of individual pathologies and their responses to standard treatments. Although every tumour is to some extent distinct, there are recurrent features of cancers that can be exploited as therapeutic targets and as prognostic and predictive biomarkers; one such attribute is telomere length. Here we discuss the utility of telomere length evaluation in cancer and describe some of the promise and challenges of bringing this into clinical practice.
} 


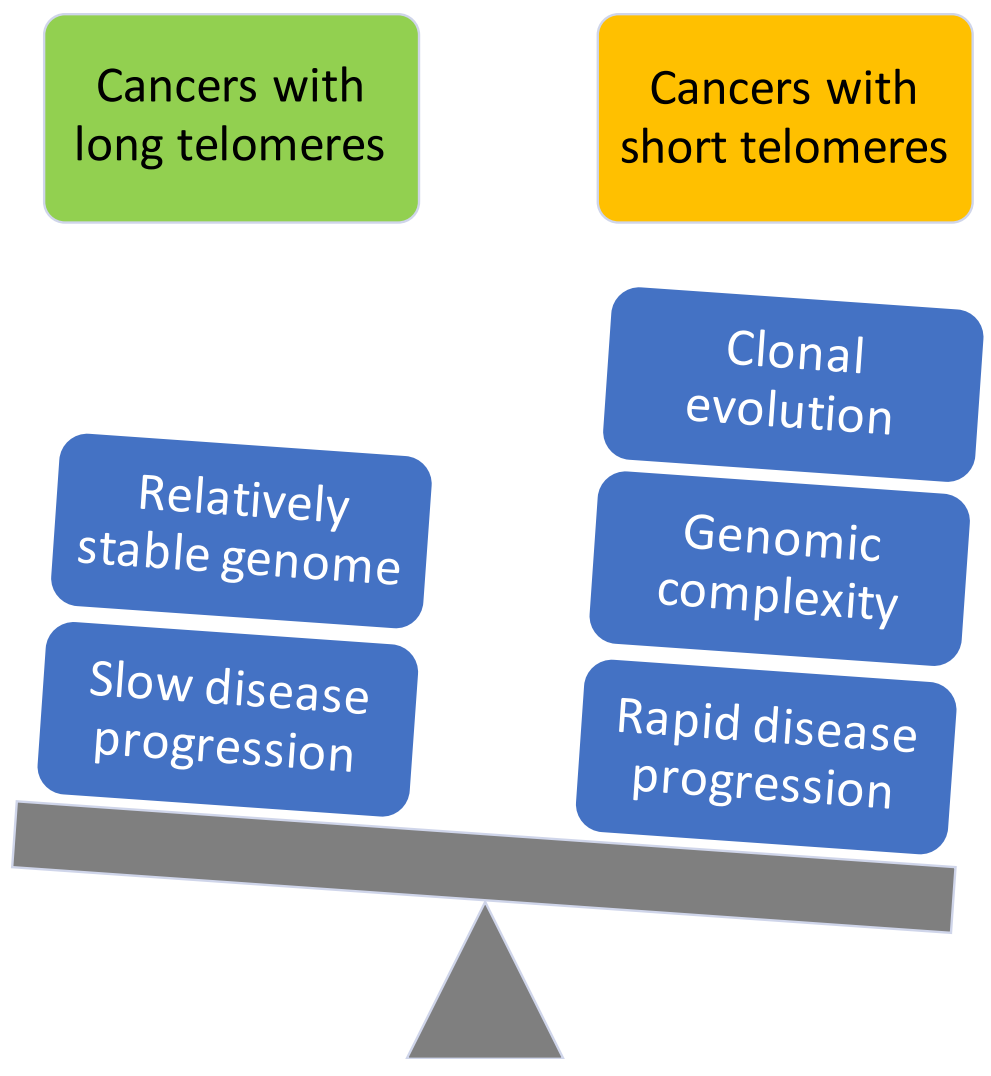

\section{Graphical abstract.}

\section{Introduction}

Telomeres are specialised structures found at the ends of all human chromosomes. They are composed of long arrays of hexameric TTAGGG repeats, which associate with a protein complex known as shelterin [1-4]. The shelterin complex protects chromosomes from endto-end fusions by preventing the ends of chromosomes from being recognised as doublestrand DNA breaks. The primary function of telomeres is to protect the integrity of exonic material and prevent genomic instability [5-8]. In the absence of telomerase, the enzyme required for telomere maintenance, telomeres erode with every cell division. This inexorable shortening of telomeres provides a so-called 'biological clock' for the cell, which ultimately limits replication and can be a trigger for apoptotic cell death $[9,10]$. However, cancer cells appear to be able to maintain telomeres to overcome cellular senescence or apoptosis caused by telomere shortening. Commonly this is facilitated by transcriptional activation of telomerase [11]. In somatic human cells, the telomerase RNA template (TERC) is constitutively expressed, whereas telomerase reverse transcriptase (TERT) expression is 
epigenetically silenced $[12,13]$. Most cancer cells acquire telomerase activity via the derepression of TERT $[13,14]$ but a subset of tumours employ the so-called alternative lengthening of telomeres (ALT) mechanism, which is a telomerase-independent means of telomere maintenance $[15,16]$.

Given the putative tumour suppressor function that telomeres play, it is tempting to speculate that inherited variation in telomere length may provide a predisposing factor to cancer development. In keeping with this concept, genome-wide association studies (GWAS) have identified 11 loci associated with variation in telomere length [17-20] and a subset of these loci harbour telomere maintenance genes. However, genetic variance can only explain a small proportion of the diversity in population telomere length. Regardless of the cause, there is a large body of evidence that telomeres and telomerase are associated with human carcinogenesis. The majority of tumour types exhibit evidence of short telomeres and crucially, some tumour telomere length profiles are short enough to result in telomere dysfunction [11,21]. Furthermore, a recent study in chronic lymphocytic leukaemia demonstrated that telomere shortening precedes the emergence of sub-clones with de novo high-risk cytogenetic aberrations and genomic complexity; all of the sub-clones had uniform telomere lengths suggesting that the clonal expansion of tumour cells with short telomeres create a permissive environment for the clonal evolution of cancer cells [22]. This finding is consistent with previous studies, which showed a strong relationship between high-risk cytogenetics and short telomeres [23-26]. In relation to telomerase, an increase in telomerase activity is often directly correlated with uncontrolled growth of cells [27]. Therefore, it is intuitive that telomere dysfunction and telomerase reactivation can contribute to a number of the hallmarks of cancer by promoting genomic instability and mutation and enabling replicative immortality and uncontrolled cell growth [28]. In turn, these characteristics can drive clonal evolution, metastatic potential and the emergence of drug resistance.

\section{Cause versus effect?}

Despite the obvious credentials that telomeres have as potential drivers of oncogenic transformation and cancer progression, the literature is full of studies that associate (normal) peripheral blood leukocyte telomere length to cancer pathologies [29-34]. As 
cancer can be viewed as an unresolved inflammatory disorder, it is perhaps not surprising that telomere erosion in leukocytes is broadly indicative of disease [35]. We might consider a paradigm in which in the early phases of tumour development cancer-associated antigens are recognised by a restricted number of immune cells, so-called immune surveillance [36]. These cognate immune cells mount a pro-inflammatory response against the cancer cell(s), which may result in cancer cell elimination. However, in some cases, this process fails due to a large number of potential factors including low antigen affinity (poor immune cell recognition), immune cell inhibition by molecules expressed on the cancer cells, and tumour-derived immunosuppressive factors secreted into the microenvironment which encourage immune cell tolerance. This is mediated through the recruitment and expansion of suppressive immune cells, such as regulatory T-cells, myeloid-derived suppressor cells, immature dendritic cells and tumour-associated macrophages [37-40]. Under these circumstances, the tumour microenvironment becomes chronically inflammatory, which in turn leads to the ineffective expansion of immune cells resulting in a process termed "inflammaging". Inflammaging may be perceived as both a cause and a consequence of malignant transformation $[41,42]$. In the context of an unresolved, pro-inflammatory microenvironment, effector immune cells may become activated and divide [43], which leads to telomere shortening and potentially even senescence. However, it seems unlikely that telomere length analysis in "by-stander" cells could ever provide the level of acuity or precision necessary for a reliable diagnosis or prognosis of a specific cancer. In addition, the application of a reductionist, mean telomere length, approach is not logical in this setting as, by definition, the analysis is carried out on a non-clonal (heterogeneous) population of peripheral blood leukocytes derived from an array of different haemopoietic stem cells (HSC). Instinctively, the originating HSCs all had different telomere lengths and their differentiated progeny will have undergone a different number of cell divisions and hence experienced differential telomere attrition. Inevitably, the analysis of this mixed cellular "soup" will manifest a much larger standard deviation of the composite telomere length distribution than would be demonstrated by a (mono)clonal expansion of cancer cells. Indeed, it might be argued that the prevalence in the literature of association studies comparing the telomere length of peripheral blood leukocytes with cancer prognosis has held back the field rather than advanced it by virtue of the inherent variability implicit in measuring telomere length in a polyclonal population of cells [44-47]. Of course, the 
demonstration of an association between non-malignant leukocyte telomere length and cancer outcomes is interesting and possibly speaks to the inflammaging phenomenon described above. However, it seems improbable that an indirect biomarker will ever have the potential to reliably diagnose or prognose individual cancer patients. This is exemplified by the wealth of contradictory data published on the prognostic significance of telomere length in a range of human cancers using this approach.

This is exacerbated by the over-simplistic dogma that short telomeres are bad and long telomeres are good; a mantra originating from a branch of the telomere field linked with ageing research. The sort of extreme telomeric erosion observed in, at least some, cancers is not analogous to the relatively modest telomere attrition usually observed in peripheral blood leukocytes during the natural ageing process. Although it is true that leukocytes derived from healthy donors can manifest minor subsets of cells with extremely short telomeres, under normal circumstances these cells would either senesce or die by apoptosis; a very different fate to that of transformed cancer cells. Furthermore, due to the re-activation of telomerase or the induction of ALT mechanisms, inferior prognosis in some forms of cancer appears to be associated with longer telomere length rather than shorter [47-49]. Our own published data on myelodysplastic syndrome, a pre-malignant prelude to the transformation to acute myeloid leukaemia (AML), showed a very clear poor prognostic signature in patients with short dysfunctional telomeres. However, in patients with de novo AML this signature was not as obvious; AML patients showed re-activation of telomerase and the homogenisation of telomere lengths [50]. So, would telomerase activity provide more insights than telomere length in these settings? Possibly, but the challenge here is methodological. Enzymatic activity assays are notoriously difficult to standardise and telomerase transcription per se does not necessarily equate to telomerase activity. Furthermore, it appears that subtle changes in telomerase activity may cause significant alterations in telomere length [51]. So, as is often the case in biology, the telomere/telomerase story is complicated and nuanced. It is therefore incumbent on the scientific community to acknowledge this, accept the limitations of some of the published literature and develop a consensus, which promotes best practice in order to shed new light on the situation. 


\section{Measuring telomeres - the long and the short of it}

As a first step, the evaluation of purified tumour cell telomere length is clearly warranted if we are to establish causation between telomere length and cancer development and/or progression. However, this does have both technical and financial implications as the tumour cells would need to be isolated and stored appropriately prior to analysis. For blood cancers this is relatively straight forward as peripheral blood samples are routinely taken to monitor disease. However, in the setting of solid cancers there is often limited material available for clinical testing and when it is available it may formalin fixed and/or paraffin embedded. These technical issues may be compounded by methodological deficiencies; the vast majority of the published studies have been carried out using quantitative polymerase chain reaction (QPCR). Although QPCR is easy to perform, it has a wide coefficient of variation, which makes interpretation of results almost impossible at the level of the individual [52-54]. This should probably disqualify this type of assay from the medical arena where diagnostic and prognostic test results are factored into clinical decision-making. An array of alternative telomere length assays exist, including terminal restriction fragment (TRF) analysis, quantitative fluorescence in situ hybridisation (Q-FISH) and flow FISH [55]. However, all of these assays have their limitations too, not least their diminished capacity to identify short dysfunctional telomeres, which in the setting of cancer appear to be important. In response to the need for an accurate telomere length measuring assay, STELA (single telomere length analysis) was developed [56,57]. Using this high-resolution telomere length test, we were able to define, for the first time, the telomere length threshold for telomere dysfunction in a human cancer [58]. Using this threshold for extreme telomere shorting allowed us to clearly identify leukaemia patients with very different clinical prognoses [59]; we have subsequently shown that the same threshold is also able to risk stratify patients with myelodysplastic syndrome, breast cancer and multiple myeloma $[50,59,60]$. A drawback of this technology is that, like flow FISH, it is technically challenging and labour intensive and is therefore not suitable for large scale studies. To address these problems, we developed a modification of the STELA assay to facilitate the high-throughput evaluation of samples (HT-STELA) [61]. This assay allows for the accurate analysis of hundreds of clinical samples with a rapid turn-around time. In a landmark study we were able to show that HT-STELA was able to predict the outcome of chronic lymphocytic leukaemia patients uniformly treated with chemoimmunotherapy [61]. Furthermore, in 
multivariate analysis telomere length, as measured using HT-STELA, was superior to all of the standard prognostic tools commonly used in the management of this disease.

\section{Conclusions}

There is growing evidence that critically short telomeres are associated with more aggressive disease and inferior outcomes in at least some human cancers. Not only is telomere length a useful prognostic biomarker, it is also emerging as a powerful predictor of response to some common types of cancer therapy. From a cancer biology standpoint, the main challenge is to prove causation between short, dysfunctional, telomeres and the development and progression of individual pathologies. From the clinical perspective, the challenges are different. The overriding concern is to validate a suitable method of telomere length measurement that can provide reliable prognostic and predictive information to patients and their clinicians. Any such validation should be carried out as part of a comprehensive biomarker study, ideally in the setting of a clinical trial, in order to determine how to optimally deploy telomere length analysis to inform the management and treatment of patients. In the first instance, telomere length could be integrated into existing prognostic scoring systems to improve their ability to risk-stratify individual patients. We have already shown that this is possible in a number of haematological cancers and the development of a reliable and fast telomere length measuring assay (HT-STELA) should now facilitate larger studies in a range of different cancers. However, there is still much work to be done before telomere length analysis becomes a routine test as a component in the realisation of precision medicine in the field of oncology.

\section{References}

1. Blackburn EH. Switching and signaling at the telomere. Cell 2001, 106:661-673.

2. Griffith JD, Comeau L, Rosenfield S, Stansel RM, Bianchi A, Moss H, de Lange T. Mammalian telomeres end in a large duplex loop. Cell 1999, 97:503-514.

3. de Lange T. Shelterin: the protein complex that shapes and safeguards human telomeres. Genes Dev 2005, 19:2100-2110.

4. Palm W, de Lange T. How shelterin protects mammalian telomeres. Ann Rev Genet 2008, 42:301-334. 
5. de Lange T. How telomeres solve the end-protection problem. Science 2009, 326:948952.

6. O'Sullivan RJ, Karlseder J. Telomeres: protecting chromosomes against genome instability. Nat Rev Mol Cell Biol 2010, 11:171-181.

7. de Lange T. Protection of mammalian telomeres. Oncogene 2002, 21:532-540.

8. Donate LE, Blasco MA. Telomeres in cancer and ageing. Phil Trans R Soc B 2011, 366:76-84.

9. Zou Y, Sfeir A, Gryaznov SM, Shay JW, Wright WE. Does a sentinel or groups of short telomere determine replicative senescence? Mol Biol Cell 2004, 15:3709-3718.

10. Von Zglinicki T, Saretzki G, Ladhoff J, d'Adda di Fagagna F, Jackson SP. Human cell senescence as a DNA damage response. Mechan Ageing Devel 2005, 26:111-117.

11. Kim NW, Piatyszek MA, Prowse KR, Harley CB, West MD, Ho PL, Coviello GM, Wright WE, Weinrich SL, Shay JW. Specific association of human telomerase activity with immortal cells and cancer. Science 1994, 266:2011-2015.

12. Feng J, Funk WD, Wang SS, Weinrich SL, Avilion AA, Chiu CP, Adams RR, Chang E, Allsopp RC, Yu J, et al. The RNA component of human telomerase. Science 1995, 269:1236-1241.

13. Nakamura TM, Morin GB, Chapman KB, Weinrich SL, Andrews WH, Lingner J, Harley CB, Cech TR. Telomerase catalytic subunit homologs from fission yeast and human. Science 1997, 277:955-959.

14. Meyerson M, Counter CM, Eaton EN, Ellisen LW, Steiner P, Caddle SD, Ziaugra L, Beijersbergen RL, Davidoff MJ, Liu Q, et al. hEST2, the putative human telomerase catalytic subunit gene, is up-regulated in tumor cells and during immortalization. Cell 1997, 90:785-795.

15. Shay JW, Bacchetti S. A survey of telomerase activity in human cancer. Eur. J. Cancer 1997, 33:787-791.

16. Heaphy CM, Subhawong AP, Hong SM, Goggins MG, Montgomery EA, Gabrielson E, Netto GJ, Epstein JI, Lotan TL, Westra WH, et al. Prevalence of the alternative lengthening of telomeres telomere maintenance mechanism in human cancer subtypes. Am J Pathol 2011, 179:1608-1615.

17. Codd V, Nelson CP, Albrecht E, Mangino M, Deelen J, Buxton JL, Hottenga JJ, Fischer K, Esko T, Surakka I, Broer L, et al, and CARDIoGRAM consortium. Identification of seven 
loci affecting mean telomere length and their association with disease. Nat Genet 2013, 45:422-427.

18. Levy D, Neuhausen SL, Hunt SC, Kimura M, Hwang SJ, Chen W, Bis JC, Fitzpatrick AL, Smith E, Johnson AD, Gardner JP, et al. Genome-wide association identifies OBFC1 as a locus involved in human leukocyte telomere biology. Proc Natl Acad Sci USA. 2010, 107:9293-9298.

19. Mangino M, Christiansen L, Stone R, Hunt SC, Horvath K, Eisenberg DT, Kimura M, Petersen I, Kark JD, Herbig U, Reiner AP, et al. DCAF4, a novel gene associated with leucocyte telomere length. J Med Genet 2015, 52:157-162.

20. Mangino M, Hwang SJ, Spector TD, Hunt SC, Kimura M, Fitzpatrick AL, Christiansen L, Petersen I, Elbers CC, Harris T, Chen W, et al. Genome-wide meta-analysis points to CTC1 and ZNF676 as genes regulating telomere homeostasis in humans. Hum Mol Genet 2012, 21:5385-5394.

21. Heaphy CM, Meeker AK. The potential utility of telomere-related markers for cancer diagnosis. J Cell Mol Med 2011, 15:1227-1238.

22. Jebaraj BMC, Tausch E, Landau DA, Bahlo J, Robrecht S, Taylor-Weiner AN, Bloehdorn J, Scheffold A, Mertens D, Böttcher S, Kneba M, et al. Short telomeres are associated with inferior outcome, genomic complexity, and clonal evolution in chronic lymphocytic leukemia. Leukemia 2019, 33:2183-2194.

- This manuscript provides direct evidence to show that telomere erosion precedes clonal evolution.

23. Guièze $R$, Pages $M$, Véronèse $L$, Combes $P$, Lemal $R$, Gay-Bellile $M$, Chauvet $M$, Callanan M, Kwiatkowski F, Pereira B, Vago P, etal. Telomere status in chronic lymphocytic leukemia with TP53 disruption. Oncotarget 2016, 7:56976-56985.

24. Sellmann L, Scholtysik R, de Beer D, Eisele L, Klein-Hitpass L, Nückel H, Dührsen U, Dürig J, Röth A, Baerlocher GM. Shorter telomeres correlate with an increase in the number of uniparental disomies in patients with chronic lymphocytic leukemia. Leuk Lymphoma 2016, 57:590-595.

25. Dos Santos P, Panero J, Palau Nagore V, Stanganelli C, Bezares RF, Slavutsky I. Telomere shortening associated with increased genomic complexity in chronic lymphocytic leukemia. Tumour Biol 2015, 36:8317-8324. 
26. Britt-Compton B, Lin TT, Ahmed G, Weston V, Jones RE, Fegan C, Oscier DG, Stankovic T, Pepper C, Baird DM. Extreme telomere erosion in ATM-mutated and 11q-deleted CLL patients is independent of disease stage. Leukemia 2012, 26:826-830.

27. Hiyama E, Hiyama K, Yokoyama T, Matsuura Y, Piatyszek MA, Shay JW. Correlating telomerase activity levels with human neuroblastoma outcomes. Nature Med 1995, 1: 249-257.

28. Hanahan D, Weinberg RA. Hallmarks of cancer: the next generation. Cell 2011, 144:646-674.

29. Luu HN, Huang JY, Wang R, Adams-Haduch J, Jin A, Koh WP, Yuan JM. Association between leukocyte telomere length and the risk of pancreatic cancer: Findings from a prospective study. PLoS One. 2019, 14:e0221697.

30. Samavat $H$, Xun X, Jin A, Wang R, Koh WP, Yuan JM. Association between prediagnostic leukocyte telomere length and breast cancer risk: the Singapore Chinese Health Study. Breast Cancer Res 2019,21:50.

31. Alves-Paiva RM, Gutierrez-Rodrigues F, Pereira-Martins DA, Figueiredo DLA, Clé DV, Conti-Freitas LC, Mamede RCM, Calado RT. Short telomere length in peripheral blood leukocytes in head and neck cancer: Findings in a Brazilian cohort. Head Neck 2019, 41:672-677.

32. Renner W, Krenn-Pilko S, Gruber HJ, Herrmann M, Langsenlehner T. Relative telomere length and prostate cancer mortality. Prostate Cancer Prostatic Dis 2018, 21:579-583.

33. Yuan JM, Beckman KB, Wang R, Bull C, Adams-Haduch J, Huang JY, Jin A, Opresko P, Newman $A B$, Zheng YL, Fenech M, Koh WP. Leukocyte telomere length in relation to risk of lung adenocarcinoma incidence: Findings from the Singapore Chinese Health Study. Int J Cancer 2018, 142:2234-2243.

34. Tahara T, Tahara S, Horiguchi N, Kawamura T, Okubo M, Ishizuka T, Yamada H, Yoshida D, Ohmori T, Maeda K, Komura N, et al. Telomere Length in Leukocyte DNA in Gastric Cancer Patients and its Association with Clinicopathological Features and Prognosis. Anticancer Res 2017, 37:1997-2001.

35. Kordinas V, Ioannidis A, Chatzipanagiotou S. The Telomere/Telomerase System in Chronic Inflammatory Diseases. Cause or Effect? Genes (Basel) 2016, 7: pii: E60.

- Manuscript linking inflammation with telomere erosion. 
36. Dunn GP, Old LJ, Schreiber RD. 2004. The three Es of cancer immunoediting. Annu. Rev. Immunol. 2004, 22:329-360.

37. Josefowicz SZ, Lu LF, Rudensky AY. Regulatory T cells: mechanisms of differentiation and function. Annu. Rev. Immunol. 2012, 30:531-564.

38. Gabrilovich DI, Nagaraj S. Myeloid-derived suppressor cells as regulators of the immune system. Nat. Rev. Immunol. 2009, 9:162-174.

39. Gabrilovich D. Mechanisms and functional significance of tumour-induced dendriticcell defects. Nat. Rev. Immunol. 2004, 4:941-952.

40. Ruffell B, Affara NI, Coussens LM. Differential macrophage programming in the tumor microenvironment. Trends Immunol. 2012, 33:119-126.

41. Bottazzi B, Riboli E, Mantovani A. Aging, inflammation and cancer. Semin Immunol $2018,40: 74-82$.

42. Leonardi GC, Accardi G, Monastero R, Nicoletti F, Libra M. Ageing: from inflammation to cancer. Immun Ageing 2018, 15:1.

43. Maimela NR, Liu S, Yi Zhang, Y. Fates of CD8+ T cells in Tumor Microenvironment. Comput. Struct. Biotec. J. 2019, 17:1-13.

44. Renner W, Krenn-Pilko S, Gruber HJ, Herrmann M, Langsenlehner T. Relative telomere length and prostate cancer mortality. Prostate Cancer Prostatic Dis. 2018, 21:579-583.

45. Tahara T, Tahara S, Horiguchi N, Kawamura T, Okubo M, Ishizuka T, Yamada H, Yoshida D, Ohmori T, Maeda K, Komura N, et al. Telomere Length in Leukocyte DNA in Gastric Cancer Patients and its Association with Clinicopathological Features and Prognosis. Anticancer Res. 2017, 37:1997-2001.

46. Pan W, Du J, Shi M, Jin G, Yang M. Short leukocyte telomere length, alone and in combination with smoking, contributes to increased risk of gastric cancer or esophageal squamous cell carcinoma. Carcinogenesis. 2017, 38:12-18.

47. Svenson U, Roos G, Wikström P. Long leukocyte telomere length in prostate cancer patients at diagnosis is associated with poor metastasis-free and cancer-specific survival. Tumour Biol. 2017, 39:1010428317692236. doi: 10.1177/1010428317692236.

48. Nan H, Du M, De Vivo I, Manson JE, Liu S, McTiernan A, Curb JD, Lessin LS, Bonner MR, Guo Q, Qureshi AA, et al. Shorter telomeres associate with a reduced risk of melanoma development Cancer Res 2011, 71:6758-6763. 
49. Lynch SM, Major JM, Cawthon R, Weinstein SJ, Virtamo J, Lan Q, Rothman N, Albanes D, Stolzenberg-Solomon RZ. A prospective analysis of telomere length and pancreatic cancer in the alpha-tocopherol beta-carotene cancer (ATBC) prevention study. Int J Cancer 2013, 133:2672-2680.

50. Williams J, Heppel NH, Britt-Compton B, Grimstead JW, Jones RE, Tauro S, Bowen DT, Knapper S, Groves M, Hills RK, Pepper C, et al. Telomere length is an independent prognostic marker in MDS but not in de novo AML. Br J Haematol 2017, 178:240-249.

51. Lansdorp PM. Maintenance of telomere length in AML. Blood Adv. 2017, 1:2467-2472.

52. Aubert G, Hills M, Lansdorp PM. Telomere length measurement - caveats and a critical assessment of the available technologies and tools. Mutat Res 2012, 730:59-67.

53. Dagnall CL, Hicks B, Teshome K, Hutchinson AA, Gadalla SM, Khincha PP, Yeager M, Savage SA. Effect of pre-analytic variables on the reproducibility of qPCR relative telomere length measurement. PLoS One 2017, 12:e0184098.

54. Lai TP, Wright WE, Shay JW. Comparison of telomere length measurement methods. Philos Trans R Soc Lond B Biol Sci 2018, 373. pii:20160451.

55. Baird DM, Rowson J, Wynford-Thomas D, Kipling D. Extensive allelic variation and ultrashort telomeres in senescent human cells. Nat Genet 2003, 33:203-207.

56. Baird DM. New developments in telomere length analysis. Exp Gerontol 2005, 40:363368.

57. Lin TT, Letsolo BT, Jones RE, Rowson J, Pratt G, Hewamana S, Fegan C, Pepper C, Baird DM. Telomere dysfunction and fusion during the progression of chronic lymphocytic leukemia: evidence for a telomere crisis. Blood 2010, 116:1899-1907.

\section{- The first definition of the telomere length threshold for telomere dysfunction.}

58. Lin TT, Norris K, Heppel NH, Pratt G, Allan JM, Allsup DJ, Bailey J, Cawkwell L, Hills R, Grimstead JW, Jones RE, et al. Telomere dysfunction accurately predicts clinical outcome in chronic lymphocytic leukaemia, even in patients with early stage disease. Br J Haematol 2014, 167:214-223.

59. Hyatt S, Jones RE, Heppel NH, Grimstead JW, Fegan C, Jackson GH, Hills R, Allan JM, Pratt G, Pepper C, Baird DM. Telomere length is a critical determinant for survival in multiple myeloma. Br J Haematol 2017, 178:94-98. 
60. Simpson K, Jones RE, Grimstead JW, Hills R, Pepper C, Baird DM. Telomere fusion threshold identifies a poor prognostic subset of breast cancer patients. Mol Oncol 2015, 9:1186-1193.

61. Norris K, Hillmen P, Rawstron A, Hills R, Baird DM, Fegan CD, Pepper C. Telomere length predicts for outcome to FCR chemotherapy in CLL. Leukemia 2019, 33:19531963.

- Evidence that telomere length is a critical determinant of response to chemoimmunotherapy. 